\title{
Enhancing effect of corticotrophin on thyrotrophin produced exophthalmos in fish
}

José M. Cañadell and Joaquin Barraquer

Department of Endocrinology, Clínica Médica "B" de la Facultad de Medicina de Barcelona and Instituto Barraquer de Oftalmología, Barcelona (Spain)

\begin{abstract}
Goldfish (Carassius auratus, var. japonicus, subvar. bicaudatus) respond to the administration of thyrotrophic hormone with exophthalmos. Eye protrusion increases with simultaneous injections of corticotrophin. Retrobulbar injections of normal saline, human serum or pituitary hormones produce a transient exophthalmos, which is much more persistent when thyrotrophin is injected. Previous treatment of fishes with longacting corticotrophin prolonged the duration of the exophthalmos caused by retrobulbar injections of thyrotrophin; this effect is not observed when other fluids are injected.
\end{abstract}

\section{INTRODUCTION}

Some fish respond with an increase in the protrusion of the ocular globes as a result of different hormonal stimuli. Albert (2) produced exophthalmos in Fundulus heteroclitus by means of intracelomic injections of anterior pituitary extracts. Dobyns and Steelman (6) showed the possibility of obtaining the same effect by injecting preparations of pituitary glands free from thyrotrophic activity. Pickford (10), on the contrary, observed that there is a strict relation between the exophthalmos-producing and thyroidstimulating effects of thyrotrophic preparations. Exophthalmos was also observed in common minnows in response to treatment with triiodothyronine and desiccated thyroid (8). On the other hand, Matty and co-workers (9) succeeded in producing exophthalmos by injecting androgens in two species of teleost fish (Sparisoma squalidum and Scarus croicensis) and by the injection of thyroxine and triiodothyronine in these species and in Bathystoma aurolineatum.

In Spain it is impossible to obtain Fundulus heteroclitus or any of the species of fish with which the authors mentioned above have worked. In a series of previous tests we investigated the possible exophthalmic action of anterior pituitary extracts in the following fish: Barbus fluviatilis, Cyprinus carpio, Leuciscus erithrophthalmus, Fundulus hispanicus, Carassius auratus, Perca fluviatilis, Tinca tinca, Gobitis fossilis, Gobius fluviatilis and Ameiurus nebulosos. All these, except the last, under diverse experimental conditions can develop exophthalmos following injections of thyrotrophin.

Nevertheless we were only able to obtain Carassius auratus var. japonicus in unlimited quantities and we used this species for almost all our investigations. Between the diverse types of goldfish, the Carassius auratus var. japonicus subvar. bicaudatus show a 
greater sensitivity and uniformity of response. This subvariety has a more globular body and a flatter head. Carassius macrophthalmus has been derived from this fish by selection; in this species protrusion of the ocular globes, which is sometimes enormous, is an inherited characteristic (Fig. 1).

We have presented numerous clinical and experimental arguments in previous papers $(4,5)$ supporting the view that the exophthalmos of Graves' disease and other related forms of ophthalmopathy (oedematous exophthalmos, malignant exophthalmos, infiltrative ophthalmopathy, exophthalmic ophthalmoplegia, etc.) are secondary to a hyperfunction of the anterior pituitary. According to Aterman (3) the adrenal cortex also participates in the pathogenesis of these conditions. Experimenting with golden hamsters we have confirmed that the presence of adrenal glands is indispensable in the production of exophthalmos by injection of thyrotrophin and that previous treatment with corticotrophin or adrenal steroids reinforces the exophthalmic action of the thyrotrophic hormone (5).

The series of experiments that follows was planned to study the effect of corticotrophin on the exophthalmos produced in Carassius auratus var. japonicus, subvar. bicaudatus by intracoelomic injections of thyrotrophin and its influence on ocular protrusion following the injection of thyrotrophin directly into the retrobulbar tissues.

\section{METHODS}

Groups of ten Carassius, about two years old $(9-10 \mathrm{~cm}$. long) were injected intracoelomically at intervals of eight hours with thyrotrophic extract, the doses varying from 0.25 to 25.00 Heyl-Laqueur units. Other similar groups were injected with corticotrophin, chorionic gonadotrophin, growth hormone, human serum and normal saline solution. The treatment was continued for 5 consecutive clays, during which the appearance of the fish was recorded and the protrusion of ocular globes measured with a caliber with vernier scale.

Other groups of goldfish were treated with the same doses of thyrotrophin but adding to each injection two international units of corticotrophin. Control groups were similarly treated with corticotrophin and chorionic gonadotrophin, growth hormone extract, human serum and normal saline solution.

In another experiment the exophthalmic effects of the retrobulbar injections of thyrotrophin were studied. The material was injected only once through the conjunctival sac of both eyes with an insulin syringe and a needle of small caliber. The dose was $0.05 \mathrm{cc}$. (5 u. Heyl-Laqueur). Control fish were injected with the same volume of corticotrophin, chorionic gonadotrophin, growth hormone and normal saline solution. The resulting ocular protrusion was measured immediately alter the injections and at regular intervals of 8 hours.

Other fish were previously treated intracoelomically with a dose of 5 i.u. of corticotrophin-zinc following which exophthalmos was brought about in the same manner as in the preceding experiment. 


\section{RESULTS}

The intracoelomic injections of thyrotrophin at doses of $10 \mathrm{u}$. Heyl-Laqueur (total quantity injected $150 \mathrm{u}$.) produced a variable exophthalmic effect. Only in two of ten injected fish was a small augmentation of the ocular protrusion and the intercorneal distance observed $(1.5 \mathrm{~mm}$. and $1.8 \mathrm{~mm}$. respectively). Administring $25 \mathrm{u}$. by injection (total dose 375 u.), exophthalmos was observed in seven fish, in four of which it was perfectly evident on simple inspection and without the necessity of measuring intercorneal distance (Fig. 2). The increase in the intercorneal distance was $3.8 \mathrm{~mm}$. $( \pm 1.15 \mathrm{~mm}$.). Doses greater than $25 \mathrm{u}$. were poorly tolerated and doses of less than $10 \mathrm{u}$. had no effect. Exophthalmos was not observed in any of the fish in the control groups injected with corticotrophin, growth hormone, chorionic gonadotrophin, human serum or normal saline solution.

In the animals showing positive results, the exophthalmos began to appear on the third day of the experiment, became more evident in the two following clays and disappeared completely at the end of two or three clays after ceasing the injections of thyrotrophin.

We observed that the injection of corticotrophin reinforced the exophthalmic effect of thyrotrophin without increasing the intensity of the maximum result. Injections of $10 \mathrm{u}$. of thyrotrophin, with a very small exophthalmic effect (see above), produced exophthalmos in six fish with increase of the intercorneal distance of $2.9 \mathrm{~mm} .( \pm 0.6$ $\mathrm{mm}$.) when it was injected with corticotrophin. Injections of $25 \mathrm{u}$. of thyrotrophin caused exophthalmos in nine fish. The evolution of exophthalmos followed the same course as in the animals injected only with thyrotrophin without complementary treatment with corticotrophin. Control groups injected with thyrotrophin and chorionic gonadotrophin, growth hormone, human serum or normal saline solution developed exophthalmos to the same degree as the fish treated with thyrotrophic hormone alone. These materials are devoid of the enhancing effect of corticotrophin.

The retrobulbar injections of a small quantity of normal saline produced a transitory increase of ocular protrusion. An augmentation of $5 \mathrm{~mm}$. or more in the intercorneal distance could thus be obtained without ill effects. This exophthalmos persisted for some four hours, then diminished progressively and disappeared in the course of the following eight hours. Injection of gonadotrophic hormone, growth hormone or human serum produced the same phenomenon, but, possibly because of the protein composition of these fluids, the exophthalmos persisted for about 24 hours. On the contrary, the exophthalmos produced by injection of thyrotrophin was always more persistent, and after 24 hours the increase of the intercorneal distance was still $80 \%$ $( \pm 6 \%)$ of the initial value and after 48 hours it was $12 \%( \pm 7 \%)$.

In the fish treated previously with corticotrophin-zinc we observed that the increase of the ocular protrusion produced by thyrotrophin was much more persistent. After 24 hours the increase in the intercorneal distance still equaled $82 \%( \pm 3 \%)$ of the initial value, after 48 hours it was $58 \%( \pm 5 \%)$ and after 72 hours it was $22 \%( \pm 10.5 \%)$ (Fig. $3)$. 


\section{DISCUSSION}

The difficulties in producing exophthalmos in some fish by injection of anterior pituitary extracts or near pure thyrotrophic preparations suggests the existence of an exophthalmic factor distinct from the thyrotrophic hormone $(1,6,7)$. Nevertheless, even though it may be unjustified to apply the results of our experiments directly as a basic explanation of the pathogenesis of the exophthalmos of Graves' disease, they confirm our hypothesis (5) that this phenomenon probably develops as a result of a combination of several endocrine factors. The action of thyrotrophic hormone is the essential causative factor; the corticotrophin and the activity of the adrenal cortex have a potentiating effect, possibly by increasing the sensitivity of the retrobulbar tissues to the exophthalmogenic action of thyrotrophin. The experiments of Langford (8) and of Matty et al. (9) in which they showed the possibility of producing exophthalmos in fish by thyroid hormones seem to oppose the thyrotrophic hypothesis, since the administration of thyroxine produces an inhibiting effect on the pituitary secretion of thyrotrophin. However, in previous experiments (5) we observed that large doses of thyroid hormone increase the thyrotrophic exophthalmos, whilst weak doses of the same are capable of reducing it. These results — apparently paradoxical—could be explained by the toxic action of the thyroxine, which is capable of stimulating the anterior pituitary-adrenal system (11), increases the corticotrophic and corticoid secretion, and indirectly creates experimental conditions analogous to those obtained by injecting thyrotrophin and corticotrophin.

\section{ACKNOWLEDGMENTS}

We are indebted to the representative in Spain of the N. V. Organon Laboratories (Oss, Holland) for their generous supply of the thyrotrophin, corticotrophin and gonadotrophic preparations used in these experiments; to Dr. S. Pagés-Maruny for providing us with growth hormone and thyrotrophic hormone; to Dr. Hernán Mínguez, of Valencia (Spain), who sent us a large quantity of different species of fish from Lake La Albufera (Valencia); to Señor A. Jonch, Director of the Zoo and Aquarium of Barcelona for allowing us to use a large number of fish from said aquarium.

\section{REFERENCES}

1. Aird, R. B.: Ann. Inter. Med. 15: 564. 1941.

2. Albert, A.: Endocrinology 40: 303. 1947.

3. Aterman, K.: Acta Endocrinol. supl. XX, vol. 15. 1954.

4. $\quad$ Cañadell, J. M. and J. Barraquer: Rev. Inform. Méd. Terap. 31: 305. 1956.

5. Cañadell, J. M., and J. Barraquer: Publ. Monog. Instituto Barraquer, No. 4. 1957.

6. Dobyns, B. M. and S. L. Steelman: Endocrinology 52: 705.1953.

7. $\quad$ Friedgood, H. B.: Bull. Johns Hopkins Hosp. 54: 48. 1934.

8. $\quad$ Langford, H. F.: Endocrinology 60: 390. 1957.

9. Matty, A. J., D. Menzel, and J. E. Bardach: J. Endocrinol. 17: 314. 1958.

10. Pickford, G. E.: Endocrinology 55: 589. 1954.

11. Swann, H. G.: Proc. Soc. Exper. Med. \& Biol. 40: 520. 1939. 


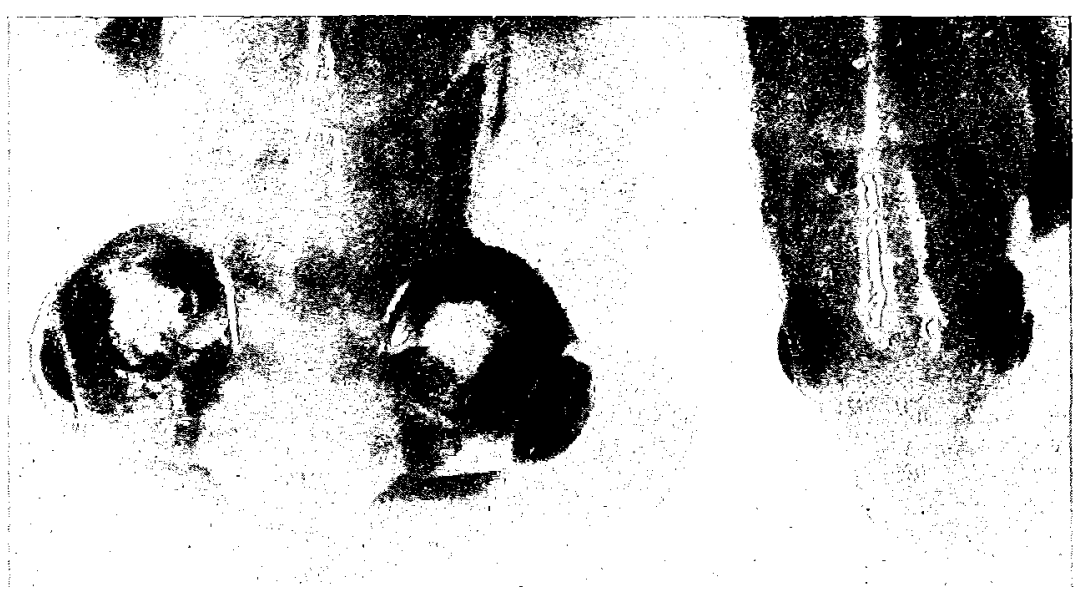

Figure 1. Telescopic-eyed goldfish (Carassius macrophthalmus) with genetic constitutional exophthalmos and a common goldfish (Carassius auratus)
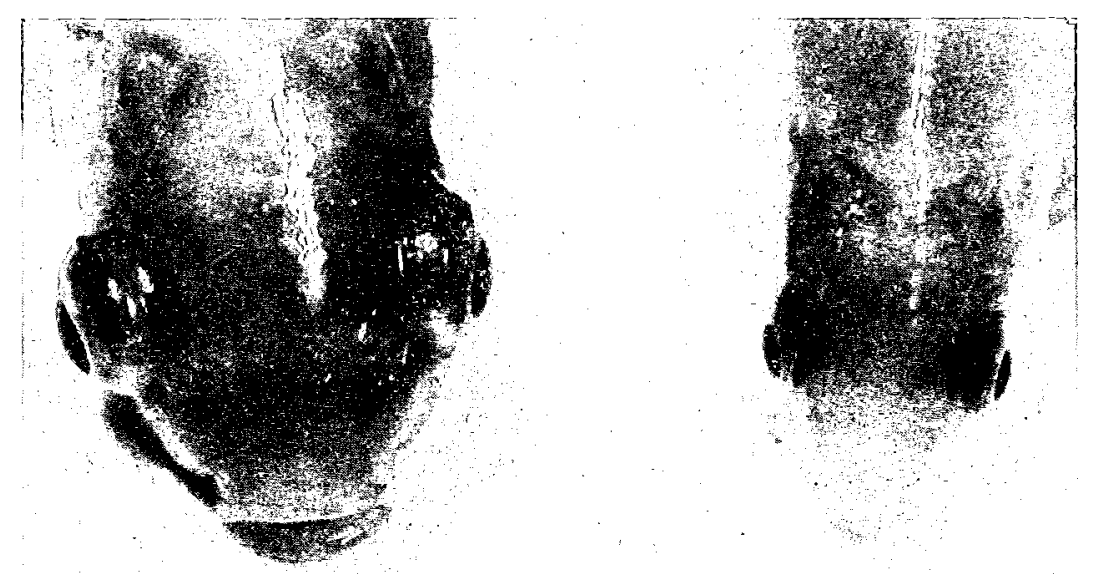

Figure 2. Exopthalmos produced with systemic treatment with thyrotrophin. At right control fish.

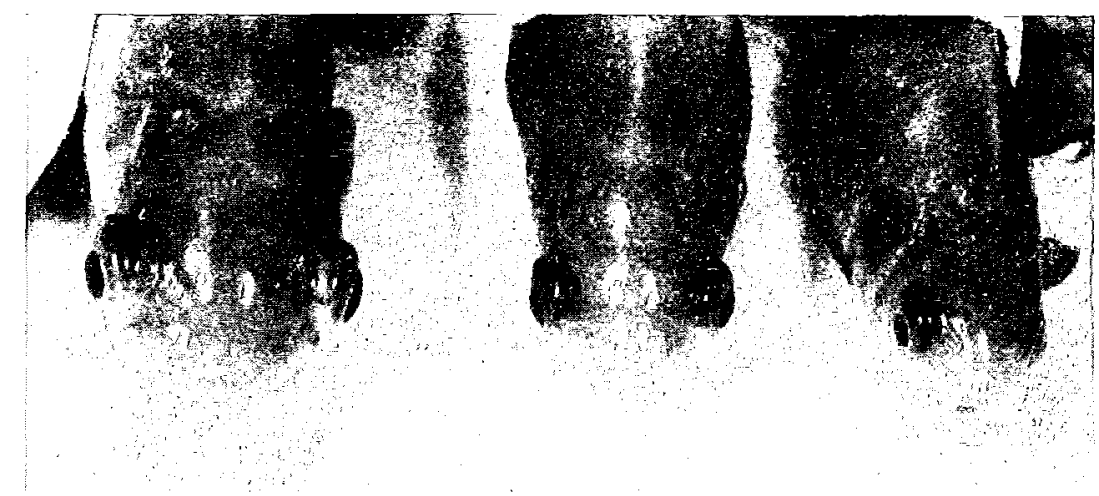

Figure 3. Ocular protrusion provoked by retrobulbar injections of thryotrophin 24 hours before. The first fish on the left was previously treated with long acting corticotrophin; the middle fish did not receive corticotrophin; on the right is the control fish in which exophthalmos was produced by injecting human serum. Note the persistence of ocular protrusion in both fish treated with thyrotrophic hormone and the larger exophthalmos in the fish that received corticotrophin. 